Louisiana State University

LSU Digital Commons

Faculty Publications

Department of Biological Sciences

$10-1-2007$

\title{
Phylogenetic conservatism and antiquity of a tropical specialization: Army-ant-following in the typical antbirds (Thamnophilidae)
}

\author{
Robb T. Brumfield \\ Louisiana State University \\ Jose G. Tello \\ Field Museum of Natural History \\ Z. A. Cheviron \\ Louisiana State University \\ Matthew D. Carling \\ Louisiana State University \\ Nanette Crochet \\ Louisiana State University
}

See next page for additional authors

Follow this and additional works at: https://digitalcommons.Isu.edu/biosci_pubs

\section{Recommended Citation}

Brumfield, R., Tello, J., Cheviron, Z., Carling, M., Crochet, N., \& Rosenberg, K. (2007). Phylogenetic conservatism and antiquity of a tropical specialization: Army-ant-following in the typical antbirds (Thamnophilidae). Molecular Phylogenetics and Evolution, 45(1), 1-13. https://doi.org/10.1016/ j.ympev.2007.07.019

This Article is brought to you for free and open access by the Department of Biological Sciences at LSU Digital Commons. It has been accepted for inclusion in Faculty Publications by an authorized administrator of LSU Digital Commons. For more information, please contact ir@lsu.edu. 


\section{Authors}

Robb T. Brumfield, Jose G. Tello, Z. A. Cheviron, Matthew D. Carling, Nanette Crochet, and Kenneth V. Rosenberg 


\title{
Phylogenetic conservatism and antiquity of a tropical specialization: Army-ant-following in the typical antbirds (Thamnophilidae)
}

\author{
Robb T. Brumfield ${ }^{\text {a,* }}$, Jose G. Tello ${ }^{\text {b,c, },}$, Z.A. Cheviron ${ }^{\text {a,d }}$, Matthew D. Carling ${ }^{\text {a,d }}$, \\ Nanette Crochet ${ }^{\mathrm{a}, 2}$, Kenneth V. Rosenberg ${ }^{\mathrm{e}}$ \\ a Museum of Natural Science, 119 Foster Hall, Louisiana State University, Baton Rouge, LA 70803, USA \\ ${ }^{\mathrm{b}}$ Field Museum of Natural History, 1400 S Lake Shore Drive, Chicago, IL 60605, USA \\ ${ }^{\mathrm{c}}$ Department of Biological Sciences, University of Illinois at Chicago, Chicago, IL 60607, USA \\ ${ }^{\mathrm{d}}$ Department of Biological Sciences, Louisiana State University, Baton Rouge, LA 70803, USA \\ e Cornell Laboratory of Ornithology, Cornell University, 159 Sapsucker Woods Road, Ithaca, NY 14850, USA
}

Received 17 August 2006; revised 1 June 2007; accepted 17 July 2007

Available online 31 July 2007

\begin{abstract}
One of the most novel foraging strategies in Neotropical birds is army-ant-following, in which birds prey upon arthropods and small vertebrates flushed from the forest floor by swarm raids of the army-ant Eciton burchellii. This specialization is most developed in the typical antbirds (Thamnophilidae) which are divisible into three specialization categories: (1) those that forage at swarms opportunistically as army-ants move through their territories (occasional followers), (2) those that follow swarms beyond their territories but also forage independently of swarms (regular followers), and (3) those that appear incapable of foraging independently of swarms (obligate followers). Although army-ant-following is one of the great spectacles of tropical forests, basic questions about its evolution remain unaddressed. Using a strongly resolved molecular phylogeny of the typical antbirds, we found that army-ant-following is phylogenetically conserved, with regular following having evolved only three times, and that the most likely evolutionary progression was from least (occasional) to more (regular) to most (obligate) specialized, with no reversals from the obligate state. Despite the dependence of the specialists on a single ant species, molecular dating indicates that army-ant-following has persisted in antbirds since the late Miocene. These results provide the first characterization of army-ant-following as an ancient and phylogenetically conserved specialization.
\end{abstract}

(C) 2007 Elsevier Inc. All rights reserved.

Keywords: Ancestral character state reconstruction; Army-ant-following; Ecological specialization; Eciton; Foraging strategies; Thamnophildae

\section{Introduction}

Army-ant-following, in which birds attending marauding army-ant swarms prey upon arthropods and small vertebrates flushed from the forest floor (Willis and Oniki, 1978), is one of the most novel foraging strategies of tro-

\footnotetext{
* Corresponding author. Fax: +1 2255783075.

E-mail address: brumfld@1su.edu (R.T. Brumfield).

${ }^{1}$ Present address: Department of Ornithology, American Museum of Natural History, Central Park West at 79th Street, New York, NY 10024, USA.

${ }^{2}$ Present address: Department of Immunology, School of Medicine, Box 357650, University of Washington, Seattle, WA 98195, USA.
}

pical regions. Such specializations have been implicated in increased tropical biodiversity by the simple fact that no ecological counterpart exists for them in temperate regions (Rahbek and Graves, 2001; Terborgh, 1985). Although it represents one of the most amazing tropical spectacles, army-ant-following has received surprisingly little research attention, particularly from an evolutionary perspective, and the bulk of our ecological knowledge of these birds stems almost entirely from the impressive collection of studies by Edwin O. Willis (e.g. Willis, 1968a,b,1969) and a recently published monograph (Willson, 2004).

One species of diurnal, swarm-raiding ant, Eciton burchelli, is the primary dependable resource for ant-following birds, frogs (Bufo marinus), and teid lizards (Ameiva, 
Kentropyx) that forage on escaping prey, for tachinid and stylopid flies that lay eggs on flushed arthropods (Rettenmeyer, 1963; Schneirla, 1971; Willis and Oniki, 1978), and for ant-butterflies that forage on the scat of armyant-following birds (Ray and Andrews, 1980). A recent coextinction study (Koh et al., 2004) characterized E. burchellii as a "keystone mutualist" because of its widespread Neotropical distribution (lowland forests more or less continuously from southern Mexico to southern Peru and Brazil) (Watkins, 1976) and the dependence of such a taxonomically diverse assemblage of organisms on it. Swarms of a second widespread army-ant species, Labidus praedator, are also followed regularly, but are a less dependable resource because they usually only swarm above ground after heavy rains (Willis and Oniki, 1978).

The army-ant-following specialization in birds can be classified more specifically as a dependence on catching prey that has been flushed by another organism (Willson, 2004). Army-ant-following woodcreepers (Dendrocolaptinae), for example, are known to also follow peccary (Tayassuidae) herds through the forest (Willis, 1966). The peccaries perform the same function for the birds as army-ants - beating prey from the forest floor. Army-antfollowing is most developed as a foraging specialization in the typical antbirds (Passeriformes: Thamnophilidae), a monophyletic (Irestedt et al., 2004), Neotropical radiation of 208 insectivorous, socially monogamous species, 94 of which attend army-ant swarms to some extent (Remsen et al., 2007; Zimmer and Isler, 2003). The specialization in antbirds has been characterized as parasitism on the army-ants, because the birds significantly reduce the rate at which the ants capture prey (Wrege et al., 2005). Antbirds that parasitize army-ant swarms compose three classes of specialization: (1) species that only forage at swarms opportunistically as army-ants move through their territory (occasional followers; 70 species), (2) species that regularly attend swarms beyond their territories, but are also often found foraging independently of swarms (regular followers; 8 species), and (3) obligate followers (16 species) that appear incapable of foraging independently of swarms or other beaters of prey (Skutch, 1996; Willis and Oniki, 1978; Willson, 2004; Zimmer and Isler, 2003). Although occasional and regular army-ant-following is also exhibited by some species in other avian families (e.g. Furnariidae, Thraupidae), obligate army-ant-following is limited to the typical antbirds (Thamnophilidae) (Pierpont, 1986; Willson, 2004).

Other than what can be inferred from the current taxonomy and a recently published phylogeny of the Thamnophilidae with taxon sampling too sparse to address the evolution of army-ant-following (Irestedt et al., 2004), nothing is known about the evolution of this remarkable specialization. Even the most basic questions concerning how army-ant-following evolved in the typical antbirds remain unanswered: Did army-ant-following evolve many times or is it phylogenetically conserved? Did its evolution progress from a less specialized to a more specialized state?
Did reversals from the most specialized state occur? Foraging substrate specialists such as army-ant-followers are often characterized as being more vulnerable to extinction, because of their dependence on a subset of the resources utilized by competing taxa (Koh et al., 2004). Assuming extinction rates are higher than rates of adaptation, army-ant-following, like any heritable adaptation to the environment, is expected to be phylogenetically conservative (Peterson et al., 1999). An important question in this regard is how long army-ant-following has persisted as a foraging strategy. Here, we present a well-supported, densely sampled phylogeny of the Thamnophilidae, which is used in conjunction with GIS analyses of species distributions to gain insights into the evolution, temporal persistence, and biogeography of this remarkable foraging strategy in antbirds.

\section{Materials and methods}

\subsection{Taxon sampling}

We sampled 70 thamnophilid species (Table 1), including individuals from all but one genus of obligate and regular army-ant-following antbird (Willis, 1968b). Taxonomy follows the checklist of the South American Classification Committee (Remsen et al., 2007) except for Myrmotherula haematonota, which we place in the new genus Epinecrophylla (Isler et al., 2006), and Sakesphorus bernardi, which we place in the genus Thamnophilus (Brumfield and Edwards, 2007). We included representatives of 40 of the 46 thamnophilid genera, and one recently rediscovered obligate ant-follower (Pithys castaneus) (Lane et al., 2006). Five of the unsampled genera do not attend ant-swarms and their likely phylogenetic relationships would not affect the analysis (Zimmer and Isler, 2003). The unsampled monotypic genus (Skutchia borbae) represents an obligate ant-follower whose likely phylogenetic placement is with Phlegopsis. Skutchia borbae was placed in the genus Phlegopsis formerly, but was elevated to generic status based on plumage differences (Willis, 1968b). Because all members of this clade are obligate army-ant-followers, excluding Skutchia will not affect the ancestral state reconstructions. Trees were rooted using four outgroup taxa (Chamaeza campanisoma, Hylopezus berlepschi, Liosceles thoracicus, and Pipra mentalis).

\subsection{Data collection}

Data for seven species were downloaded from Genbank (Brumfield and Edwards, 2007; Tello and Bates, 2007): Thamnomanes caesius (EF030197, EF030259, EF030288, EF030320), Cymbilaimus lineatus (EF030221, EF030254, EF030283, EF030315), Frederickena unduligera (EF030222, EF030255, EF030284, EF030316), Sakesphorus luctuosus, (EF030225, EF030258, EF030287, EF030319), Thamnophilus doliatus (EF030234, EF030267, EF030296, 
Table 1

Ingroup taxa used in this study with collector and frozen tissue collection voucher number (Louisiana State University Museum of Zoology, LSUMZ; Field Museum of Natural History, FMNH; Burke Museum of Natural History, UWBM; United States National Museum, USNM; University of Alaska Museum (UAM))

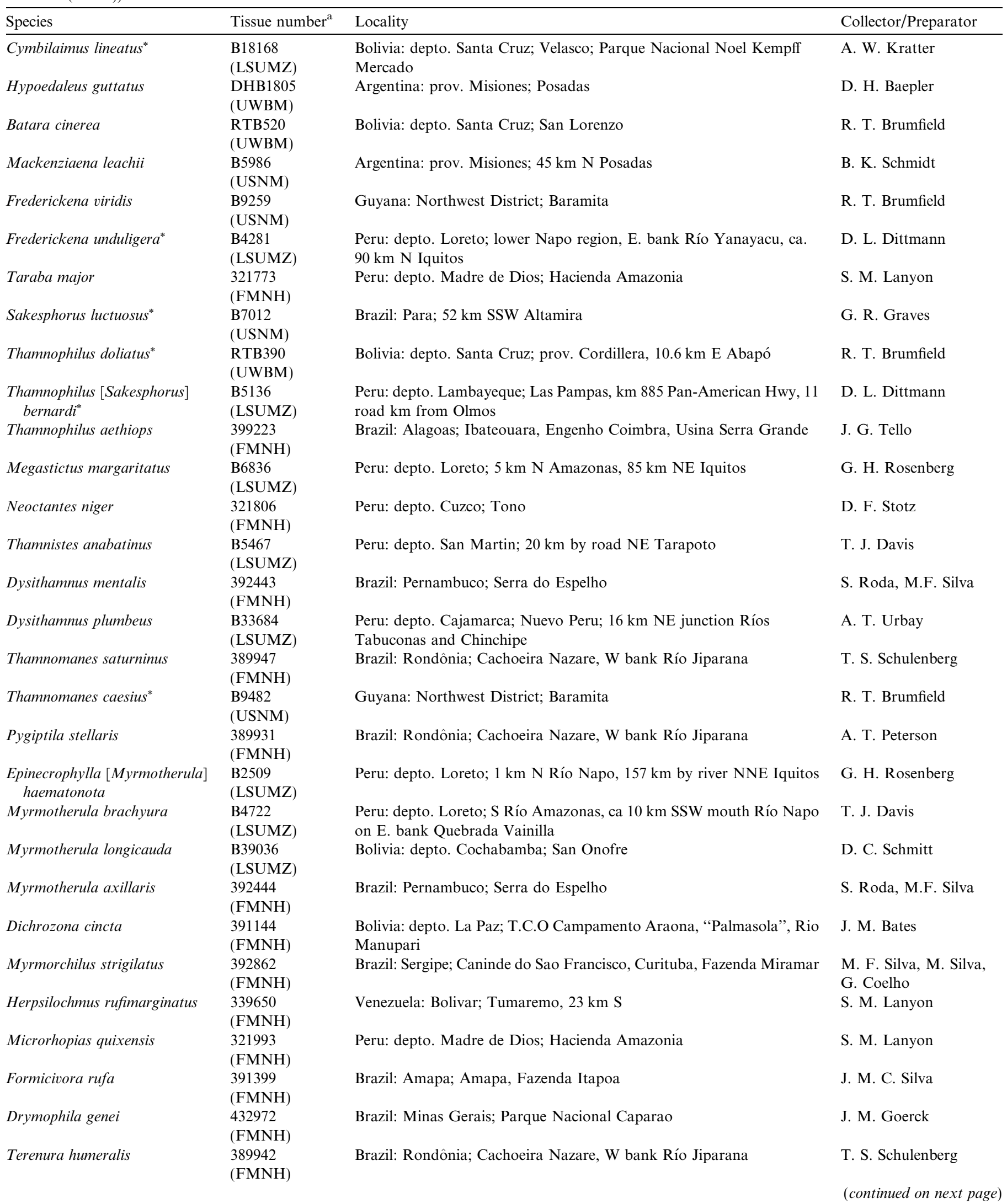


Table 1 (continued)

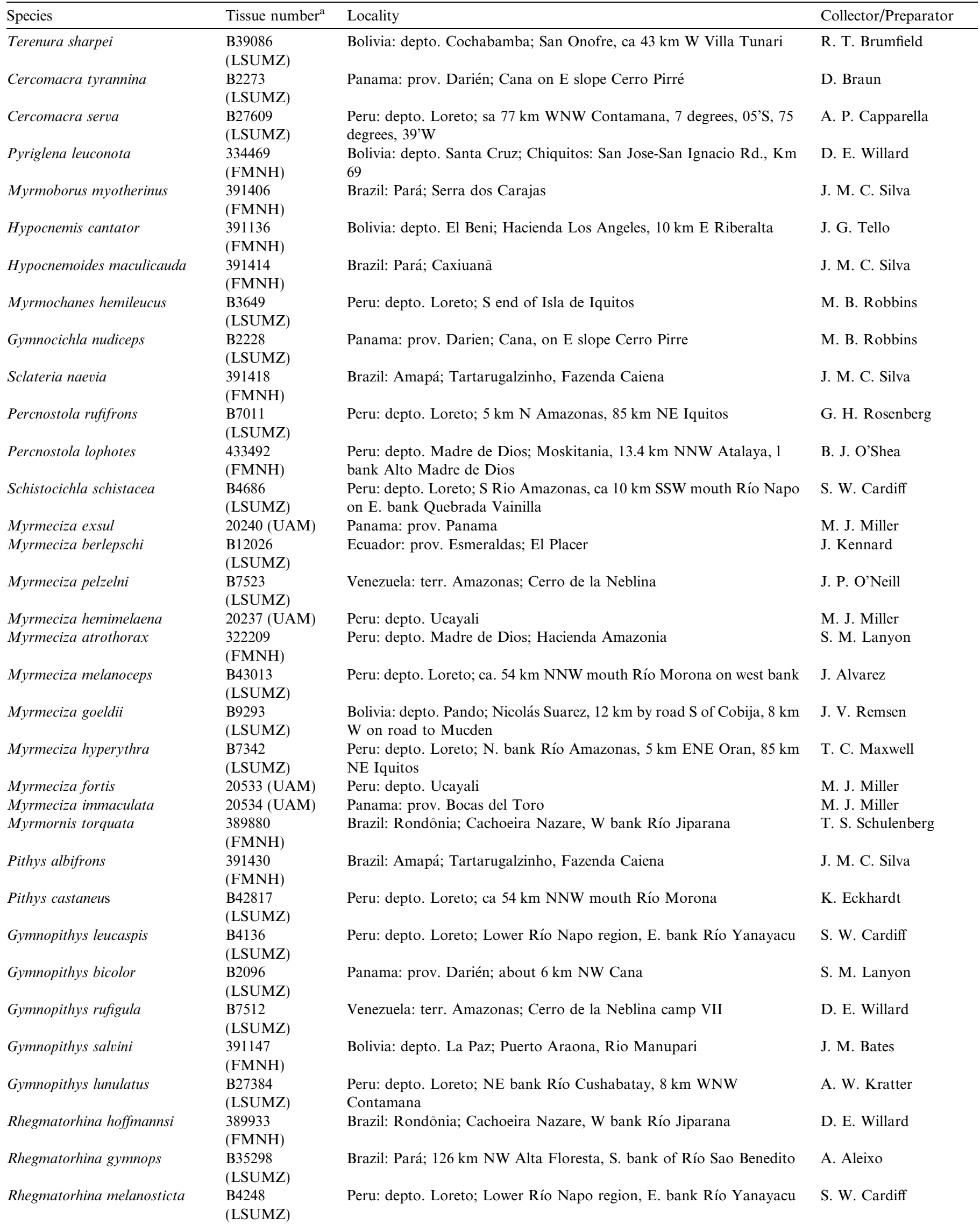


Table 1 (continued)

\begin{tabular}{|c|c|c|c|}
\hline Species & Tissue number ${ }^{\mathrm{a}}$ & Locality & Collector/Preparator \\
\hline Hylophylax naevioides & $\begin{array}{l}\text { B2230 } \\
\text { (LSUMZ) }\end{array}$ & Panama: prov. Darien; $5 \mathrm{~km} \mathrm{~N}$ Amazonas, $85 \mathrm{~km} \mathrm{NE} \mathrm{Iquitos}$ & G. H. Rosenberg \\
\hline Hylophylax punctulatus & $\begin{array}{l}\text { B18327 } \\
\text { (LSUMZ) }\end{array}$ & $\begin{array}{l}\text { Bolivia: depto. Santa Cruz; Velasco; Parque Nacional Noel Kempff } \\
\text { Mercado, } 86 \text { km ESE Florida }\end{array}$ & M. D. Cardeño \\
\hline Hylophylax poecilinotus & $\begin{array}{l}391148 \\
(\mathrm{FMNH})\end{array}$ & $\begin{array}{l}\text { Bolivia: La Paz; T.C.O. Campamento Araona, "Palmasola", Rio } \\
\text { Manupari }\end{array}$ & J. M. Bates \\
\hline Phlegopsis nigromaculata & $\begin{array}{l}389842 \\
(\mathrm{FMNH})\end{array}$ & Brazil: Rondônia; Cachoeira Nazare, W bank Río Jiparana & D. E. Willard \\
\hline Phlegopsis erythroptera & $\begin{array}{l}\text { B9617 } \\
\text { (LSUMZ) }\end{array}$ & $\begin{array}{l}\text { Bolivia: depto. Pando; Nicolás Suarez, } 12 \mathrm{~km} \text { by road S of Cobija, } 8 \mathrm{~km} \\
\mathrm{~W} \text { on road to Mucden }\end{array}$ & D. C. Schmitt \\
\hline Phaenostictus mcleannani & $\begin{array}{l}\text { B2135 } \\
\text { (LSUMZ) }\end{array}$ & Panama: prov. Darien; ca 6 km NW Cana & M. B. Robbins \\
\hline
\end{tabular}

Sequences for species denoted with an asterisk downloaded from Genbank. The phylogenetic tree was rooted using the following outgroup taxa: Chamaeza campanisona (Formicariidae: KGB14 [UWBM]), Hylopezus berlepschi (Formicariidae: 322345 [FMNH]), Liosceles thoracicus (Rhinocryptidae: 390080 [FMNH]), Pipra mentalis* (Pipridae: B18078 [LSUMZ]).

EF030327), Thamnophilus bernardi (EF030223, EF030256, EF030285, EF030317), and Pipra mentalis (DQ294404, DQ294491, DQ294535, DQ294448). From all other individuals, we sequenced portions of three mitochondrial protein-coding genes (ND2, ND3, cyt $b$ ) and one nuclear intron ( $\beta$-fibrinogen intron 5). DNA was extracted from $25 \mathrm{mg}$ of pectoral muscle using DNeasy kits (Qiagen Inc., Valencia, CA). In a $25 \mu 1$ total volume, PCR amplifications contained approximately $50 \mathrm{ng}$ of genomic template DNA, $1.5 \mathrm{mM}$ $\mathrm{MgCl}_{2}, 200 \mathrm{mM}$ dNTPs, and $0.1 \mathrm{U}$ Promega Taq or AmpliTaq (Applied Biosystems, Inc., Foster City, CA). Thermocycling consisted of an initial denaturation step $\left(94{ }^{\circ} \mathrm{C}\right.$ for $2 \mathrm{~min}$ ) followed by 35 cycles of $94^{\circ} \mathrm{C}$ for $1 \mathrm{~min}$, a $30 \mathrm{~s}$ annealing step (ND2, ND3, cyt $b: 45^{\circ} \mathrm{C}, \beta$-fibrinogen intron 5: $50{ }^{\circ} \mathrm{C}$ ), and a $72{ }^{\circ} \mathrm{C}$ extension for $1 \mathrm{~min}$. To facilitate cloning of PCR products through addition of an adenine to all amplicons, a $7 \mathrm{~min}$ extension at $72{ }^{\circ} \mathrm{C}$ was performed as the final step. PCR primers and internal sequencing primers are presented in Table 2. Amplicons were purified using PEG precipitation, eluted in $12.5 \mu \mathrm{l}$ of $\mathrm{diH}_{2} \mathrm{O}$, and sequenced directly with an ABI Prism cycle sequencing kit (Applied Biosystems Inc.) and an ABI 3100 Genetic Analyzer. Sequencing reactions were purified with AutoSeq G-50 spin columns (Amersham Biosciences, Piscataway, NJ). Both strands were sequenced.

\subsection{Phylogenetic analysis}

Sequences were aligned manually using Sequencher 4.1.2 (Gene Codes Corporation, Ann Arbor, MI). Protein-coding mitochondrial sequences were translated into amino acids to verify the absence of stop codons or other anomalous residues. Maximum-likelihood and Bayesian methods were the primary methods of phylogenetic analysis. The optimal maximum-likelihood model for each gene and the combined data set was chosen using the program ModelTest (Posada and Crandall, 1998) to perform hierarchical likelihood ratio tests on a series of nested models (Swofford et al., 1996). Likelihood scores to use in these tests were calculated for each model on a neighbor-joining tree (Saitou and Nei, 1987) reconstructed from the raw percent sequence divergence distance matrix using PAUP* (Swofford, 2003). With the optimal maximum-likelihood model, the most-likely tree for each gene and the combined data set was reconstructed with the program PAUP* using heuristic searches with 10 random-addition replicates and TBR branch-swapping. A parsimony analysis of the concatenated data was also performed with all sites weighted equally and the same heuristic search parameters as in the likelihood analysis, except 100 random-addition replicates were used.

Table 2

List of primers used in PCR amplification and cycle sequencing

\begin{tabular}{|c|c|c|c|}
\hline Gene & Primer & Sequence $\left(5^{\prime} \Rightarrow 3^{\prime}\right)$ & Location \\
\hline cyt $b$ & L14990 & CCA TCC AAC ATC TCA GCA TGA TGA AA & L14990 (cyt $b$ ) \\
\hline cyt $b$ & H16065 & AAC TGC AGT CAT CTC CGG TTT ACA AGA C & H16065 (tRNA $\left.{ }_{\text {Thr }}\right)$ \\
\hline cyt $b$ & cytb.intf & CAC GAR ACY GGR TCY AAY AAY CC & L15496 (internal) \\
\hline cyt $b$ & cytb.intr & GGR TTR TTR GAY CCR GTY TCG TG & H15496 (internal) \\
\hline ND2 & L5215 & TAT CGG GCC CAT ACC CCG AAA AT & L5193 (tRNA Met $)$ \\
\hline ND2 & H6313 & CTC TTA TTT AAG GCT TTG AAG GC & $\mathrm{H} 6313\left(\mathrm{tRNA}_{\mathrm{Trp}}\right)$ \\
\hline ND2 & L5758 & GGN GGN TGR RBH GGN YTD AAY CAR AC & L5733 (internal) \\
\hline ND2 & H5766 & DGA DGA RAA DGC YAR RAY YTT DCG & H5766 (internal) \\
\hline ND3 & L10755 & GAC TTC CAA TCT TTA AAA TCT GG & L10733 (tRNA $\left.A_{\text {Gly }}\right)$ \\
\hline ND3 & H11151 & GAT TTG TTG AGC CGA AAT CAA C & $\mathrm{H} 11154\left(\mathrm{tRNA} \mathrm{Arg}_{\mathrm{Arg}}\right)$ \\
\hline$\beta f 5$ & FIB5L & CGC CAT ACA GAG TAT ACT GTG ACA T & S713 \\
\hline$\beta \mathrm{f5}$ & FIB5H & GCC ATC CTG GCG ATC TGA A & AS767 \\
\hline
\end{tabular}

The mitochondrial primers are numbered according to location in the Gallus genome (Desjardins and Morais, 1990) and the $\beta$-fibrinogen external primers with regard to a Gallus cDNA sequence (Weissbach et al., 1991). 

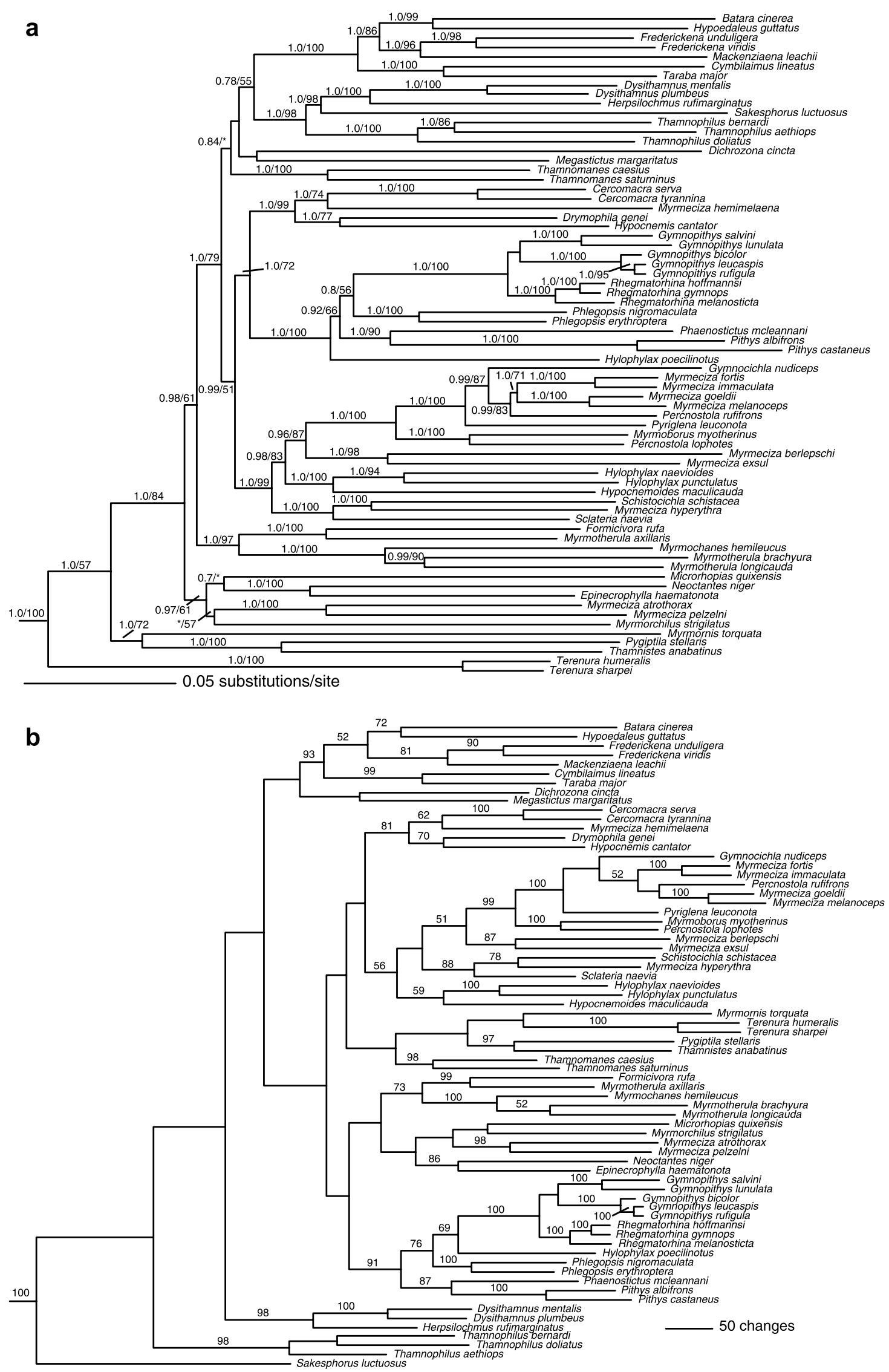

Fig. 1. Maximum-likelihood (a) and most parsimonious (b) trees from heuristic searches of the concatenated data matrix. Bayesian (before slash) and bootstrap (after slash) support values presented for the maximum-likelihood tree. Bootrap support values presented for the parsimony tree. Trees rooted using four outgroup taxa (not pictured). 
To assess nodal support in the phylogeny, the optimal maximum-likelihood models for each data set (cytochrome $b$, ND2, ND3: GTR + G+ I; b-fibrinogen intron 5: $\mathrm{HKY}+\mathrm{G}$ ) were used in a site-partitioned Bayesian analysis (Table 3). Uniform interval priors were assumed for the parameters, except for base frequencies, which were assigned a Dirichlet prior (Huelsenbeck and Ronquist, 2001). Four heated chains were run for $5.0 \times 10^{6}$ generations, and sampled every 1000. Trees from the first $5.0 \times 10^{5}$ generations were discarded as "burn-in", with the remaining 4501 trees from the stationary distribution used to estimate posterior probabilities of tree topology and other maximum-likelihood parameters, including transition rates between army-ant-following behaviors (see ancestral character state reconstruction section below). Three independent runs with different random seeds were performed to insure the posterior probabilities were stable. We also assessed nodal support using 100 maximum-likelihood and parsimony non-parameteric bootstrap replicates using the same heuristic search options described above.

\subsection{Ancestral character state reconstruction}

To reconstruct the evolutionary history of army-ant-following, we coded each species as (1) a non-follower or occasional follower (these are operationally the same because nearly all understory insectivores will follow a swarm if it moves through their territory), (2) a regular follower, or (3) an obligate follower. Ancestral character state reconstructions for this multi-state character were performed using both parsimony (Maddison and Maddison, 2000; Maddison, 1990) as well as maximum-likelihood and Bayesian Markov Chain Monte Carlo (MCMC) methods that incorporate a statistical model of trait evolution (Mooers and Schluter, 1999; Ronquist, 2004). Bayesian methods have the advantage of building into the analysis uncertainty about both the process of character change

Table 3

Summary of model parameters and tree scores for maximum-likelihood and Bayesian analyses for all taxa

\begin{tabular}{llllll}
\hline & ND2 & ND3 & cyt $b$ & $\beta f 5$ & Combined \\
\hline \# Trees & 1 & 2 & 1 & 1 & 1 \\
$-\ln (L)$ & 22542.1 & 6891.7 & 19292.3 & 4514.7 & 54484.5 \\
$r_{\text {AC }}$ & 0.283 & 0.469 & 0.285 & 1.486 & 0.409 \\
$r_{\text {AG }}$ & 13.797 & 7.212 & 9.473 & 4.081 & 7.616 \\
$r_{\text {AT }}$ & 0.458 & 0.333 & 0.785 & 0.747 & 0.529 \\
$r_{\text {CG }}$ & 0.385 & 0.208 & 0.179 & 1.558 & 0.335 \\
$r_{\text {CT }}$ & 7.326 & 7.212 & 9.473 & 4.081 & 7.616 \\
$\alpha$ & 0.669 & 0.829 & 0.768 & 2.247 & 0.703 \\
$p_{\text {iv }}$ & 0.341 & 0.401 & 0.488 & NA & 0.372 \\
freq(A) & 0.378 & 0.360 & 0.355 & 0.307 & 0.360 \\
freq $(C)$ & 0.361 & 0.357 & 0.390 & 0.159 & 0.345 \\
freq(G) & 0.049 & 0.067 & 0.055 & 0.206 & 0.073 \\
freq(T) & 0.212 & 0.216 & 0.200 & 0.328 & 0.223 \\
\hline
\end{tabular}

The maximum-likelihood parameters were used in bootstrap analyses of the data. NA indicates parameters that were not estimated. and the phylogeny (Huelsenbeck et al., 2003; Pagel et al., 2004). Bayesian MCMC ancestral state reconstructions and character transition rate estimations were performed using the program BayesMS (Buschbom and Barker, 2006; Pagel et al., 2004). The set of trees used in the Bayesian character analysis were the same 4501 trees generated by MrBayes (Huelsenbeck and Ronquist, 2001) to estimate nodal confidence in the phylogeny. On each tree in the set, the maximum-likelihood rates of character change were estimated using a uniform prior. Phylogenetic uncertainty was accounted for by averaging the estimates across the set of 4501 trees. Ancestral state probabilities for a given node were estimated by multiplying the mean ancestral probability at that node across all trees by the proportion of the trees in which the node was found as determined by the Bayesian phylogenetic analysis (see Phylogenetic analysis section above) (Pagel et al., 2004). Parsimony reconstructions were performed using MacClade (Maddison and Maddison, 2000), and assumed equal transition rates between all character states.

\subsection{Dating ancestral nodes}

Two molecular clock calibrations available for mitochondrial variation in birds equate 1.6\% (Fleischer et al., 1998 ) or $2.0 \%$ sequence divergence (Shields and Wilson, 1987 ) with one million years of evolution. The $1.6 \%$ calibration is based on cyt $b$ variation in Hawaiian oscine passerines and may be more applicable to suboscine passerine antbirds than the $2.0 \%$ rate, which was derived from mitochondrial RFLP variation in geese. To date relevant ancestral nodes in the antbird phylogeny, we first reduced the dataset to just the cyt $b$ sequences and used a parametric likelihood ratio test to examine whether the genetic variation was consistent with a molecular clock. On a tree composed of the species in Fig. 1 and with the same topology, parameters in the GTR $+\mathrm{G}+\mathrm{INV}$ substitution model were estimated with and without a clock constraint and the likelihood calculated. The test statistic is two times the absolute difference in log likelihood scores. To generate a null distribution, we used the program Seq-Gen (Rambaut and Grassly, 1997) to evolve 100, 1045-bp long sequences along the topology according to the substitution model parameters that had been optimized on the unconstrained tree (rate matrix $=2.349221 .39812 .11280 .3466$ 36.4922 ; base frequencies $=0.30030 .35120 .1154$; shape parameter $=1.4852 ;$ proportion of invariant sites $=$ 0.5282 ). On each simulated data set, the model parameters were optimized with and without a clock constraint and the likelihoods calculated. Statistical significance at a level of $\alpha=0.95$ would occur if the test statistic fell into the top $5 \%$ of values in the simulated distribution.

\subsection{GIS analyses}

To examine the geographical context of army-ant-following in light of the phylogeny, we constructed antbird 


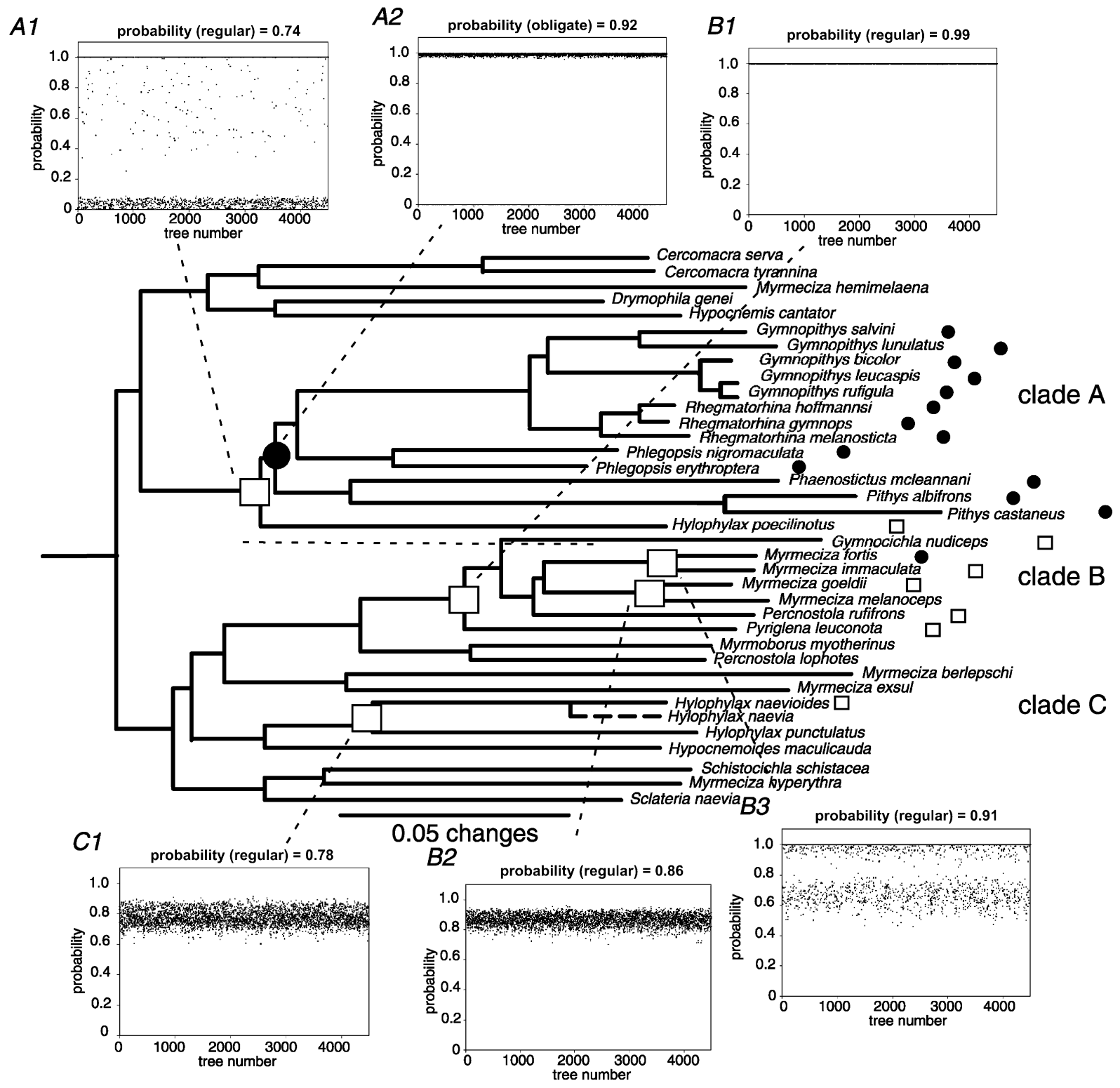

Fig. 2. Bayesian posterior probabilities of army-ant-following (circle: obligate, square: regular, all other taxa are occasional/non-followers), mapped onto relevant ancestral nodes of a maximum-likelihood phylogeny of the Thamnophilidae. To improve the visibility of ancestral node reconstructions only the portion of the tree containing army-ant-following taxa is depicted. Graphs show maximum-likelihood reconstructed node at each of 4501 MCMC-trees sampled from the posterior probability distribution. Independent origin of army-ant-following highlighted in clades A, B, and C. Nodal support is presented above branches (Bayesian posterior probabilities before forward slash, maximum-likelihood bootstrap after forward slash) except for those nodes having less than 0.5 Bayesian posterior probability and less than $50 \%$ bootstrap value.

species density maps for each of the three foraging categories as well as for the species in the sister clades to clades A, B, and C (see Online Supplementary Material). ArcView shape files containing distribution maps (Ridgely et al., 2003) of thamnophilid and furnariid species were downloaded from InfoNatura (2005). To construct species density maps, we created a $50 \times 50 \mathrm{~km}$ grid that encompassed the entire Neotropical region (9380 cells) using ArcView GIS 3.3 (ESRI 2003) with the Area Tools extension. We determined the grid cells that each species occurred in by overlaying species distributions onto the grid in ArcView. Species distributions were converted to $50 \times 50 \mathrm{~km}$ grids by selecting those cells that intersected the species distribu- tions. The number of species that occurred in each grid cell was then tallied and mapped. Because regular army-antfollowing furnariids (ovenbirds) compete with antbirds and are part of the dominance hierarchy (Willson, 2004), we performed a second analysis that included the regular furnariid army-ant-followers (Willis and Oniki, 1978).

\section{Results}

\subsection{Sequence variation and phylogenetic analyses}

All data from this study were deposited into TreeBASE (Accession No. S1805). Sequences of cyt $b$ (1045 bp, 
a occasional and non-followers (thamnophilids)

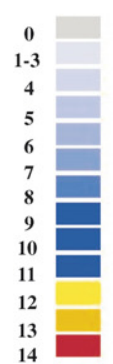

C regular followers (thamnophilids and furnariids)

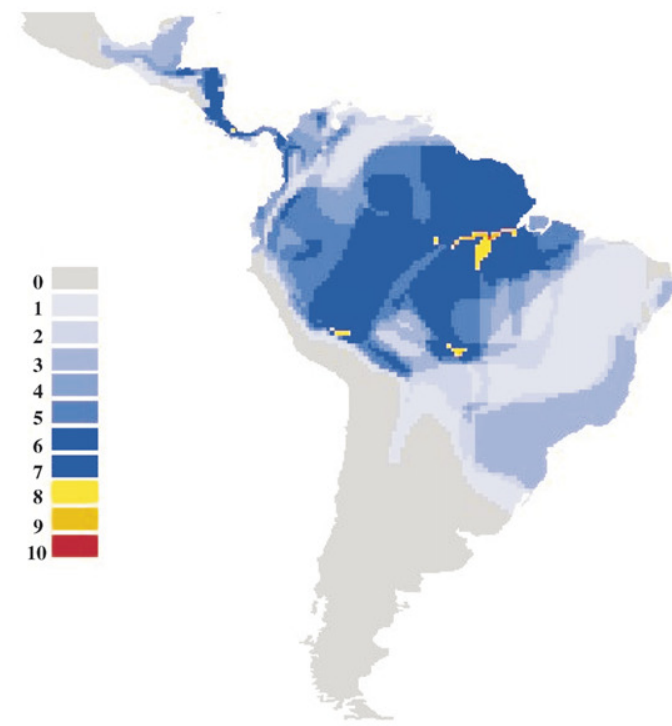

b obligate thamnophilid followers

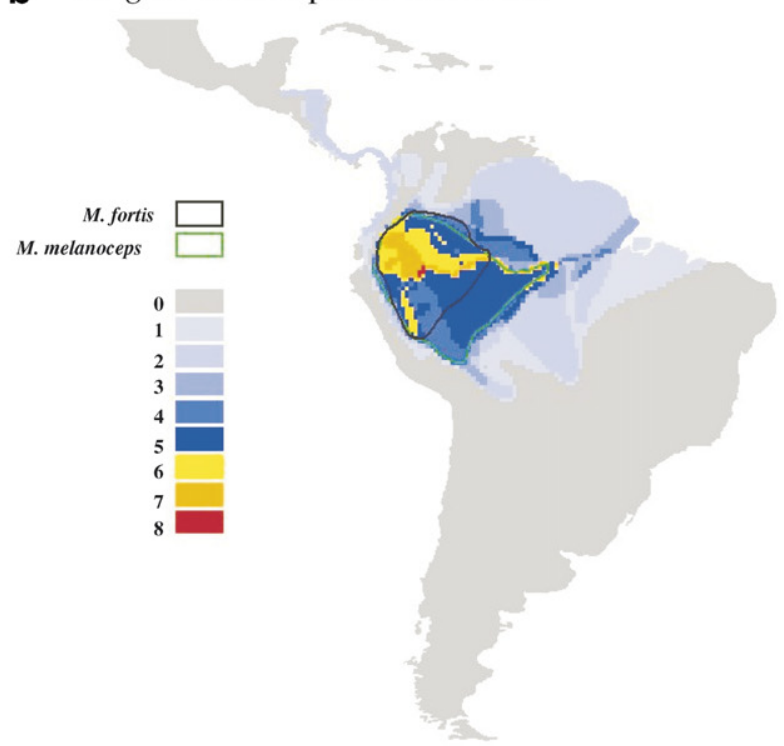

d regular followers (thamnophilids)

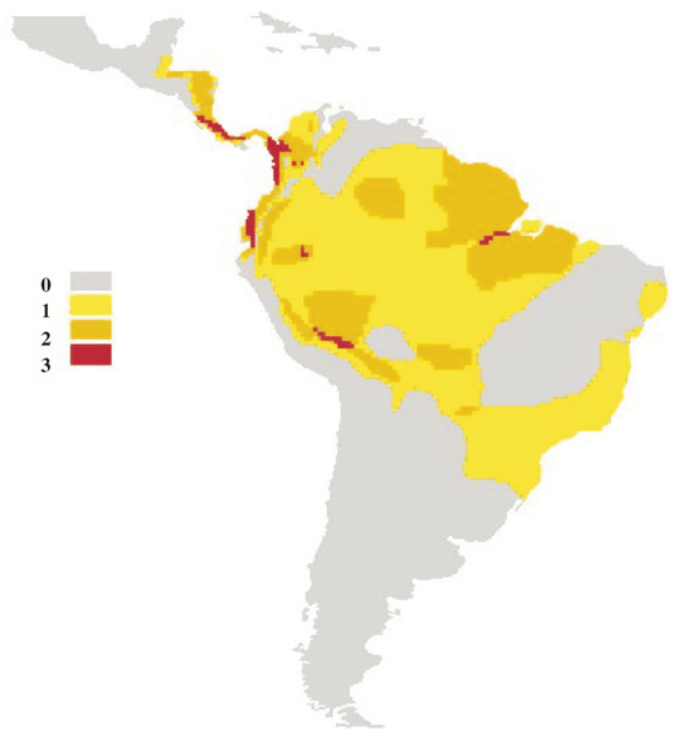

Fig. 3. Species-richness maps of (a) occasionallnon-following species that are sister to ant-following clades A, B, and C (Fig. 1); (b) obligate army-antfollowers, with distributions of Myrmeciza fortis (obligate) and M. melanoceps (occasional) outlined; (c) regular army-ant-followers (pooling thamnophilid and furnariid species); (d) regular thamnophilid army-ant-followers.

corresponding to bases $14,991-16,035$ of the chicken mitochondrial genome), ND2 (1041 bp, corresponding to bases 5220-6280), ND3 (351 bp, corresponding to bases 10,776$11,126)$, and $\beta f 5(571 \mathrm{bp})$ were obtained for most taxa (Genbank Accession Nos. EF639874-EF640139), creating a total data set of $2977 \mathrm{bp}$. Missing from the data set were Bf5 for Myrmeciza berlepschi and Myrmotherula brachyura. Thirty-one base-pairs of difficult-to-align $\beta f 5$ sequence were excluded from all analyses. No stop codons or other anomalous amino acid residues were detected in the mitochondrial protein-coding sequences. Homogeneity of base frequencies across all taxa was not rejected for any of the data sets $(P>0.05)$.
A partition homogeneity test found no significant differences $(P>0.05)$ in phylogenetic signal among the trees reconstructed from the individual genes. In addition, Shimodaira-Hasegawa tests (Shimodaira and Hasegawa, 1999) found no significant disagreement in the topologies of phylogenies reconstructed from the individual genes. Phylogenetic analysis of the combined data set resulted in a single most-likely tree $(-\ln L=54484.5)$, with the majority of nodes supported by high $(>70 \%)$ non-parametric bootstraps and posterior probabilities greater than 0.95 (Fig. 1a). The parsimony analysis resulted in a single most parsimonious tree $(12,865$ steps), but the strongly supported nodes were found only near the tips of the tree 
(Fig. 1b). Other weighting schemes that could have produced a more strongly supported parsimony tree were not explored.

\subsection{Ancestral character state reconstruction}

To address the evolutionary progression of army-antfollowing and whether reversals from army-ant-following were observed, we estimated ancestral character states using parsimony and Bayesian methods. Most posterior probabilities of the ancestral states fell below the statistically significant 0.95 level, reflecting the uncertainty inherent in ancestral character state reconstruction. Both parsimony and Bayesian ancestral state reconstructions indicated that regular army-ant-following evolved independently three times in the typical antbirds from occasional army-ant-following ancestors (see clades $\mathrm{A}, \mathrm{B}$, and $\mathrm{C}$ in Fig. 2), with two of these lineages (clades $A$ and $B$ ) leading eventually to obligate army-ant-following. Army-ant-following represents a derived state in the typical antbirds that is phylogenetically conserved.

Ancestral nodes at the base of the obligate clades A and B (Fig. 2) had ambiguous character states based on parsimony reconstructions, but Bayesian reconstructions suggest the evolution of army-ant-following was progressive, following a chronological specialization sequence from occasional to regular to obligate. In clade A, the common ancestor of Hylophylax poecilinotus (a regular follower) and its large sister clade of obligate followers was a regular follower with 0.74 posterior probability (Fig. 2). Similarly, the common ancestor of Myrmeciza fortis (an obligate follower) and M. immaculata (a regular follower) was a regular follower with a posterior probability of 0.91 .

We did not observe evolutionary reversals from the most specialized obligate state, but did detect one reversal from regular following ancestors. Myrmeciza melanoceps, an occasional follower, is embedded within a clade of regular and obligate followers and the ancestral reconstruction suggests its most recent common ancestor was a regular follower $($ posterior probability $=0.86)($ Fig. 2$)$.

\subsection{Dating ancestral nodes}

A parametric likelihood ratio test did not reject $(P=0.18)$ clock-like evolution of the thamnophilid cyt $b$ sequences. Using an estimate of $1.6 \%$ cyt $b$ sequence divergence per million years derived from a study of Hawaiian honeycreepers (Fleischer et al., 1998), we made a very rough estimate that the common ancestor of "obligatelregular" ant-following clade A (Fig. 2) existed approximately 6.4 Mya (late Miocene), and the common ancestor of the largely regular ant-following clade B occurred approximately 4.2 Mya (early Pliocene).

\subsection{GIS analyses}

We were interested in examining whether the only reversal we observed, a shift from regular to occasional following in M. melanoceps, occurred in a region of the Neotropics with a relatively high number of co-occurring army-ant-following antbirds. Assuming competition would be most intense in such a region, this could suggest a role for competition in the reversal. We were also interested in whether $M$. fortis, the only obligate follower in clade B, occurred in the same region. Willson's (2004) community ecology study of army-ant-following birds in southeastern Peru found that $M$. fortis preferred following swarms of $L$. praedator. Intense competition at $E$. burchellii swarms could influence the evolution of such a preference. Our GIS analysis revealed that the number of co-occurring obligate armyant-following species is highest in western Amazonia (Fig. 3b), the region in which both $M$. melanoceps and M. fortis occur. In contrast, the densities of regular followers were highest around the periphery of the Amazon basin (Fig. 3d).

\section{Discussion}

This evolutionary analysis of army-ant-following found it to be an ancient and phylogenetically conserved tropical foraging specialization, with a history largely consistent with theoretical expectations of the progression of specializations. What was most surprising was that the evolutionary vulnerability to coextinction hypothesized to accompany specialization was not observed in army-antfollowing antbirds. Despite the dependence of army-antfollowers on a single "keystone" army-ant species (Koh et al., 2004), army-ant-following appears to have persisted in thamnophilid antbirds since the late Miocene. This timeframe postdates the advent of diurnal army-ant swarming in $E$. burchellii and L. praedator that occurred after these species diverged 20-40 million years ago (Brady, 2003). A recent analysis that examined the tempo of mitochondrial evolution in birds found that the above calibrations likely lead to underestimates of divergence times (Pereira and Baker, 2006), so that the evolution of army-ant-following in the typical antbirds could be even older than 6 million years.

Our results suggest that the evolution of army-ant-following most likely followed a progression from least specialized to most specialized. This result makes intuitive sense in light of the unique behavioral traits associated with some regular and most obligate followers. In addition to their ant-following behavior, obligate and some regular army-ant-following antbirds are distinguished by specialized behaviors, such as not defending exclusive territories and "bivouac-checking" (Swartz, 2001; Willson, 2004). If some amount of neurological canalization is associated with these behaviors, reversals to less specialized states may be evolutionarily constrained. Accordingly, we did not observe reversals from obligate following in either clade $\mathrm{A}$ or $\mathrm{B}$, and we observed only one reversal from regular to occasional army-ant-following in clade B. Because of the limited number of independent contrasts inherent in this study, phylogenetic studies of army-ant-following in other 
bird families will be needed to bolster our conclusions regarding evolutionary reversals from the army-ant-following specialization. Whether such an evolutionary progression is characteristic of other novel avian foraging strategies in the tropics awaits additional comparative studies (Thompson, 1994). The dead-leafing foraging specialization (Greenberg and Gradwohl, 1980) exhibited by other antbird species was recently shown to be phylogenetically conserved in the Thamnophilidae (Hackett and Rosenberg, 1990; Isler et al., 2006).

The GIS analyses of species distributions suggest that competition could have played a role in the evolution and distribution of army-ant-following in antbirds, although we note that other explanations need to be explored. The hierarchical division of swarms into a series of concentric feeding zones, with the largest ant-followers occupying the most productive leading edge of the advancing swarm and the smallest species at the trailing edge (Willis and Oniki, 1978), accommodates the co-existence of army-ant-followers at a single swarm. Interspecific competition among species is intense (Willson, 2004), and the relatively low number of obligate thamnophilid species suggests an ecological limit on the resource, perhaps policed through competition. In this regard, the lone obligate army-ant-follower of clade B, M. fortis, is noteworthy in that the species (1) evolved its obligate army-ant-following behavior more recently than obligate army-ant-following in clade A, assuming the molecular branch lengths are proportional to time (Fig. 2), and (2) minimizes competition with other obligate army-ant-followers by spending a greater proportion of time following $L$. praedator swarms instead of those of E. burchellii (Willson, 2004), the premier swarmer attended by clade A species. The distribution of M. fortis occurs western Amazonia, a region with the highest number of co-occurring obligate army-ant-following species (Fig. 3b). Similarly, the reversal from regular to occasional army-ant-following observed in $M$. melanoceps (clade B; Fig. 2) could have been induced by competition, because this species also occurs in western Amazonia.

If competition at swarms impacts the distribution of army-ant-followers, we expected to find the evolution of regular followers in regions with fewer obligate followers. For example, the lone army-ant-follower of clade $\mathrm{C}$ (Fig. 2), Hylophylax naevioides, occurs as a regular armyant-follower in the forested lowlands west of the Andes, where there are only two obligate species (Gymnopithys bicolor and Phaenostictus mcleannani). Interestingly, the two other species in clade C, Hylophylax naevia (not included in this study, but known to be part of this clade; Brumfield, unpublished data) and Hylophylax punctulata, occur syntopically with up to five obligate ant-followers east of the Andes. Neither H. naevia nor $H$. punctulata follows ants more than occasionally. Could the regular armyant-following behavior of $H$. naevioides have evolved because there were only two obligate competitors west of the Andes? The ant-following species density maps illustrate clear differences between obligate and regular followers. Obligate army-ant-followers are found almost exclusively in Amazonia, with increasing densities moving westward towards the Andes. This same pattern was observed in the occasional/non-follower map and with patterns found in a meta-analysis of all species of breeding birds in South America (Rahbek and Graves, 2001). In contrast to this general pattern, regular followers were most abundant where obligates were least prevalent or absent - in the Atlantic coastal forests of Brazil, the Guyanan shield, and the forested lowlands west of the Andes (Fig. 3c and d). This pattern was evident both when thamnophilids were analyzed alone (Fig. 3d) and in concert with furnariids (Fig. 3c). Collectively, these results suggest competition could have played a role in the evolution of armyant-followers and shaping the distribution of army-ant-following species. Field studies are needed to test this and other possibilities.

Critical caveats to our interpretation of the above distribution patterns are that we did not consider the population densities of the ants across their distributions, nor seasonal variation in ant-swarming. The population densities of $E$. burchellii and $L$. praedator have undoubtedly influenced the distribution and densities of army-ant-following birds. For example, in the Guyanas, where the density of obligate followers is relatively low (Fig. 3), population densities of E. burchellii also appear to be low (B. J. O'Shea, pers. comm.). Unfortunately, detailed data on the population densities of army-ants across their distributions are unavailable to the best of our knowledge. Higher elevation and drier forests around the periphery of Amazonia experience increased seasonality that could reduce the yearround availability of swarms.

It also remains to be seen if the evolution of army-antfollowing had any demonstrable impact on rates of diversification or extinction in the lineages in which it evolved. Too few independent contrasts were available in the current analysis to address these issues with statistical power, so a future test is dependent on the availability of well-supported phylogenies of other bird families containing armyant-following species.

\section{Acknowledgments}

Studies such as this would be impossible were it not for the long-term efforts of ornithologists working at great expense to collect samples from remote corners of Central and South America. For collecting tissue samples of the species used in this study, we are extremely grateful to the collectors and specimen preparators whose names appear in Table 1, and to the curators and collections managers of the Louisiana State University Museum of Zoology (LSUMZ), the Field Museum of Natural History (FMNH), University of Washington's Burke Museum of Natural History (UWBM), the United States National Museum of Natural History (USNM), and the University of Alaska Museum (UAM) for loaning to us the tissues used in this study. For comments on the manuscript or assistance in the lab we thank J. M. 
Bates, J. Blackwell, A. Curtis, K. Feldheim, S. J. Hackett, J. Prejean, J. V. Remsen, F. H. Sheldon, and four anonymous reviewers. The map data were provided by NatureServe in collaboration with Robert Ridgely, James Zook, The Nature Conservancy-Migratory Bird Program, Conservation International - CABS, World Wildlife Fund - US, and Environment Canada - WILDSPACE. This research was supported by National Science Foundation Grants DEB0543562 and DBI-0400797 to R.T.B., and INT-0135532 to J.G.T and J. M. Bates.

\section{Appendix A. Supplementary data}

Supplementary data associated with this article can be found, in the online version, at doi:10.1016/j.ympev. 2007.07.019.

\section{References}

Brady, S.G., 2003. Evolution of the army-ant syndrome: the origin and long-term evolutionary stasis of a complex of behavioral and reproductive adaptations. Proc. Natl. Acad. Sci. USA 100, 65756579.

Brumfield, R.T., Edwards, S.V., 2007. Evolution into and out of the Andes: a Bayesian analysis of historical diversification in Thamnophilus antshrikes. Evolution 61, 346-367.

Buschbom, J., Barker, D., 2006. Evolutionary history of vegetative reproduction in Porpidia s. $l$. (lichen-forming ascomycota). Syst. Biol. 55, 471-484.

Desjardins, P., Morais, R., 1990. Sequence and gene organization of the chicken mitochondrial genome. A novel gene order in higher vertebrates. J. Mol. Biol. 212, 599-634.

Fleischer, R.C., McIntosh, C.E., Tarr, C.L., 1998. Evolution on a volcanic conveyor belt: using phylogeographic reconstructions and K-Ar-based ages of the Hawaiian Islands to estimate molecular evolutionary rates. Mol. Ecol. 7, 533-545.

Greenberg, R., Gradwohl, J., 1980. Leaf surface specializations of birds and arthropods in a Panamanian forest. Oecologia 46, 115-124.

Hackett, S.J., Rosenberg, K.V., 1990. Comparison of phenotypic and genetic differentiation in South American antwrens (Formicariidae). Auk 107, 473-489.

Huelsenbeck, J.P., Nielsen, R., Bollback, J.P., 2003. Stochastic mapping of morphological characters. Syst. Biol. 52, 131-158.

Huelsenbeck, J.P., Ronquist, F., 2001. MrBayes: Bayesian inference of phylogeny. Biometrics 17, 754-755.

InfoNatura: birds, mammals, and amphibians of Latin America [web application], 2005. Version 4.1. Arlington, Virginia (USA): NatureServe. $<$ http://www.natureserve.org/infonatura $>$.

Irestedt, M., Fjeldså, J., Nylander, J.A.A., Ericson, P.G.P., 2004. Phylogenetic relationships of typical antbirds (Thamnophilidae) and test of incongruence based on Bayes factors. BMC Evol. Biol..

Isler, M.L., Lacerda, D.R., Isler, P.R., Hackett, S.J., Rosenberg, K.V., Brumfield, R.T., 2006. Epinecrophylla, a new genus of antwrens (Aves: Passeriformes : Thamnophilidae). Proc. Biol. Soc. Wash. 119, 522-527.

Koh, L.P., Dunn, R.R., Sodhi, N.S., Colwell, R.K., Proctor, H.C., Smith, V.S., 2004. Species coextinctions and the biodiversity crisis. Science 305, 1632-1634.

Lane, D.F., Valqui, H.T., Alonso, J.A., Armenta, J., Eckhardt, K., 2006. Solving an ornithological mystery: the rediscovery and natural history of the White-masked Antbird (Pithys castaneus). Wilson J. Ornithol. $118,13-22$

Maddison, D.R., Maddison, W.P., 2000. MacClade: analysis of phylogeny and character evolution. Vers. 4.0. Sinauer, Sunderland, MA.
Maddison, W.P., 1990. A method for testing the correlated evolution of two binary characters: are gains or losses concentrated on certain branches of a phylogenetic tree. Evolution 44, 539-557.

Mooers, A.O., Schluter, D., 1999. Reconstructing ancestor states with maximum likelihood: support for one- and two-rate models. Syst. Biol. 48, 623-633.

Pagel, M., Meade, A., Barker, D., 2004. Bayesian estimation of ancestral character states on phylogenies. Syst. Biol. 53, 673-684.

Pereira, S.L., Baker, A.J., 2006. A mitogenomic timescale for birds detects variable phylogenetic rates of molecular evolution and refutes the standard molecular clock. Mol. Biol. Evol. 23, 1731-1740.

Peterson, A.T., Soberon, J., Sanchez-Cordero, V., 1999. Conservatism of ecological niches in evolutionary time. Science 285, 1265-1267.

Pierpont, N., 1986. Interspecific aggression and the ecology of woodcreepers (Aves: Dendrocolaptidae). Ph.D. dissertation, Princeton University, Princeton, New Jersey.

Posada, D., Crandall, K.A., 1998. MODEL-TEST: testing the model of DNA substitution. Bioinformatics 14, 817-818.

Rahbek, C., Graves, G.R., 2001. Multiscale assessment of patterns of avian species richness. Proc. Natl. Acad. Sci. USA 98, 4534 4539.

Rambaut, A., Grassly, N.C., 1997. Seq-Gen: an application for the Monte Carlo simulation of DNA sequence evolution along phylogenetic trees. Comput. Appl. Biosci. 13, 235-238.

Ray, T.S., Andrews, C.S., 1980. Antbutterflies: butterflies that follow army ants to feed on antbird droppings. Science 210, 1147-1148.

Remsen Jr., J.V., Cadena, C.D., Jaramillo, A., Nores, M., Pacheco, J.F., Robbins, M.B., Schulenberg, T.S., Stiles, F.G., Stotz, D.F., Zimmer, K.J., 2007. A classification of the bird species of South America. American Ornithologists' Union, version 28 May 2007. <www. museum.lsu.edu/ Remsen/SACCBaseline.html $>$.

Rettenmeyer, C.W., 1963. Behavioral studies of army ants. Univ. Kans. Sci. Bull. 44, 281-465.

Ridgely, R.S., Allnutt, T.F., Brooks, T., McNicol, D.K., Mehlman, D.W., Young, B.E., Zook, J.R., 2003. Digital distribution maps of birds of the Western Hemisphere, version 1.0. NatureServe, Arlington, VA.

Ronquist, F., 2004. Bayesian inference of character evolution. Trends Ecol. Evol. 19, 475-481.

Saitou, N., Nei, M., 1987. The neighbor-joining method: a new method for reconstructing phylogenetic trees. Mol. Biol. Evol. 4, 406-425.

Schneirla, T.C. (Ed.), 1971. Army Ants: a study in social organization. W.H. Freeman and Co., San Francisco.

Shields, G.F., Wilson, A.C., 1987. Calibration of mitochondrial DNA evolution in geese. J. Mol. Evol. 24, 212-217.

Shimodaira, H., Hasegawa, M., 1999. Multiple comparisons of loglikelihoods with applications to phylogenetic inference. Mol. Biol. Evol. 16, 1114-1116.

Skutch, A., 1996. Antbirds and ovenbirds. University of Texas Press, Austin.

Swartz, M.B., 2001. Bivouac checking, a novel behavior distinguishing obligate from opportunistic species of army-ant-following birds. Condor 103, 629-633.

Swofford, D.L., 2003. PAUP*. Phylogenetic Analysis Using Parsimony (*and Other Methods). Sinauer Associates, Sunderland, MA.

Swofford, D.L., Olsen, G.J., Waddell, P.J., Hillis, D.M., 1996. Phylogenetic inference. In: Hillis, D.M., Moritz, C., Mable, B.K. (Eds.), Molecular Systematics. Sinauer Associates Inc., Sunderland, MA, pp. 407-514.

Tello, J.G., Bates, J.M., 2007. Molecular phylogenetics of the tody-tyrant and flatbill assemblage of tyrant flycatchers (Tyrannidae). Auk 124, 134-154.

Terborgh, J., 1985. Habitat selection in Amazonian birds. In: Cody, M.L. (Ed.), Habitat Selection in Birds. Academic Press, New York, pp. 311-338.

Thompson, J.N., 1994. The Coevolutionary Process. University of Chicago Press, Chicago.

Watkins, J.F., 1976. The identification and distribution of New World army ants (Dorylinae: Formicidae). Baylor University Press, Waco, Texas. 
Weissbach, L., Oddoux, C., Procyk, R., Grieninger, G., 1991. The $\beta$ chain of chicken fibrinogen contains an atypical thrombin cleavage site. Biochemistry 30, 3290-3294.

Willis, E.O., 1966. Interference competition and the foraging behavior of plain-brown Woodcreepers. Ecology 47, 667-671.

Willis, E.O., 1968a. Studies of the behavior of Lunulated and Salvin's antbirds. Condor 70, 128-148.

Willis, E.O., 1968b. Taxonomy and behavior of pale-faced Antbirds. Auk $85,253-264$.

Willis, E.O., 1969. On the behavior of five species of Rhegmatorhina, antfollowing antbirds of the Amazon basin. Wilson Bull. 81, 362-395.
Willis, E.O., Oniki, Y., 1978. Birds and army ants. Ann. Rev. Ecol. Syst. 9 , 243-263.

Willson, S.K., 2004. Obligate army-ant-following birds: a study of ecology, spatial movement patterns, and behavior in Amazonian Peru. Ornithol. Monogr. 55, 1-67.

Wrege, P.H., Wikelski, M., Mandel, J.T., Rassweiler, T., Couzin, I.D., 2005. Antbirds parasitize foraging army ants. Ecology 86, 555-559.

Zimmer, K.J., Isler, M.L., 2003. Family Thamnophilidae (Typical Antbirds). In: del Hoyo, J., Elliott, A., Christie, D.A. (Eds.), Handbook of the Birds of the World, Broadbills to Tapaculos, 8 . Lynx Edicions, Barcelona, pp. 448-681. 